contacts is associated with practices in deprived areas. ${ }^{24}$ This study clearly shows that high rates also exist in more privileged areas, and we believe that this phenomenon is due to patients expecting a 24 hour general medical service.

1 Jarman B. Identification of underprivileged areas. $\mathrm{Br}$ Med $\mathcal{F}$ 1983;286:1705-9.

2 Livingstone AE, Jewell JA, Robson J. Twenty four hour care in inner cities: two years' out of hours workload in east London general practice. Br Med $\mathcal{f}$ 1989;299:368-70.

3 Whitby M, Freeman G. GPs' differing responses to out-of-hours calls Practitioner 1989;223:493-5.

4 Usherwood TP, Kapasi MA, Barber JH. Wide variations in the night visiting rate. $7 R$ Coll Gen Pract 1985;35:395.

5 Marsh GN, Horne RA, Channing DM. A study of telephone advice in managing out-of-hours calls. IR Coll Gen Pract 1987;37:301-4

6 Sheldon MG, Harris SJ. Use of deputising services and night visit rates in general practice. Br Med f 1984;289:474-6.

7 Bain DJG. Deputising services: the Portsmouth experience. Br Med $f$ 1984:289:471-3.
.

1984;289:471-3.
Ridsdill Smith RM. Out-of-hours calls. Update 1983;26:274-7.

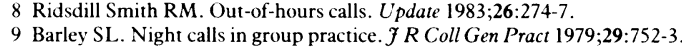

10 Morton DJ. Night calls in a group practice. $\mathcal{F} R$ Coll Gen Pract 1979;29:305-8.

11 Riddel JA. Out-of-hours visits in a group practice. Br Med f 1980;280:1518-9.
12 Lockstone DR. Night calls in a group practice. $\mathcal{f} R$ Coll Gen Pract 1976;26:68-71.

13 Cunningham RJ. Night calls in a single-handed rural practice. $f R$ Coll Gen Pract 1980;30:745-7.

14 Crowe MGF, Hurwood DS, Taylor RW. Out-of-hours calls in a Leicestershire practice. Br.Med f 1976;i:1582-4.

15 Tulloch AJ. "Out-of-hours" calls in an Oxfordshire practice. Practitioner 1984;228:663-6

16 General Medical Services Committee. Annual report 1988. Appendix XIII. London: British Medical Association, 1988:43.

17 Weingarten MA. Telephone consultations with patients: a brief study and review of the literature. $\mathcal{f} R$ Coll Gen Pract 1982;32:766-70.

18 Orton DI, Gruzelier JH. Adverse changes in mood and cognitive performance of house officers after night duty. Br Med f 1989;298:21-3

19 Poulton EC, Hunt GM, Carpenter A, Edwards RS. The performance of junior hospital doctors following reduced sleep and long hours of work. Ergonomics 1978:21:279-95.

20 Friedman RC, Kornfeld DS, Bigger TJ. Psychological problems associated with sleep deprivation in interns. F Med Educ 1973;48:436-41.

21 Neighbour R. The inner consultation. Lancaster: MTP Press, 1987:235-6.

22 Chambers RM. The health of general practitioners: a cause for concern? $7 R$ Coll Gen Pract 1989;39:179-81.

23 Pitts J. Hours of work and fatigue in doctors. $\mathcal{F}$ R Coll Gen Pract 1988;38:2-3. 24 Main JA, Main PGN. Twenty four hour care in inner cities. Br Med $\mathcal{F}$ 1989;299:627

(Accepted 22 February 1990)

\title{
Health checks in general practice: another example of inverse care?
}

\author{
Deborah Waller, Martyn Agass, David Mant, Angela Coulter, Alice Fuller, Lesley Jones
}

Berinsfield Health Centre, Berinsfield, Oxford OX9 $8 \mathrm{NE}$

Deborah Waller, $\mathrm{MB}$, general practice trainee Martyn Agass, MRCGP, general practitioner

Imperial Cancer Research Fund Practice Research Group, University Department of Community Medicine and General Practice, Gibson Building, Radcliffe Infirmary, Oxford OX2 6HE

David Mant, MRCGP, clinical lecturer in general practice Alice Fuller, BSC, research officer

Lesley Jones, BA, computer scientist

Unit of Clinical Epidemiology, University of Oxford, Oxford Angela Coulter, MSC, primary care research officer

Correspondence to: Dr Mant.
Abstract

Objective-To assess attendance at and the characteristics of patients attending health checks for cardiovascular disease offered in a general practice over a period of five years (1984-9).

Design-Medical record audit and postal questionnaire survey.

Setting-One general practice in Oxfordshire with a socially diverse population.

Participants-1101 Men and 1110 women aged 35-64 registered with the practice.

Main outcome measures-Age, sex, marital state, social class, smoking habits, alcohol consumption, and diet.

Results - Of the 2211 men and women in the target age group (35-64) in 1989, $1458(65.9 \%)$ had been offered screening and $963(43.6 \%)$ had attended for a health check. Attenders were more likely to be women, aged $\geqslant 45$, married, non-smokers, and of higher social class than patients who did not respond to the invitation. The relative likelihood of nonattendance was 1.24 for smokers, 1.20 for the overweight, 1.16 for heavy drinkers, and 1.28 for those with a less healthy diet, even after adjustment for age, sex, marital state, and social class.

Conclusions-After five years of offering health checks, opportunistically (to men) and in the context of cervical smear tests (to women), less than half of the eligible patients had attended. The likelihood of acceptance of an invitation to attend was inversely related to the patient's cardiovascular risk for all factors measured except age. A coherent strategy to reduce cardiovascular disease depends on more careful targeting of scarce health service resources and more emphasis on public health measures (such as dietary regulation and tobacco taxation). Doctors should be careful not to absolve the government of its public health obligations by substituting unproved preventive interventions aimed at the individual patient.

\section{Introduction}

The government has made it clear in its white paper Promoting Better Health that it will require general practitioners to participate further in preventive care and health education. ${ }^{1}$ The new contract states that general practitioners will be obliged, under their terms of service, to provide preventive services for all patients aged 16-74 years. ${ }^{2}$ Sessional fees will be introduced for health promotion clinics (for example, well person, heart disease, antismoking, alcohol control, diet management, stress management, and diabetes). The value of these activities remains a matter of debate, but even in subjects that are comparatively uncontroversial, such as screening for hypertension, there is apprehension that Hart's inverse care law ${ }^{3}$ will prevail and that patients at highest risk will not take up the services offered. Pill et al have characterised those who attend preventive clinics as "the worried well." 45

At Berinsfield Health Centre the treatment room nurses have been offering health checks to men and women aged 35-64 years for five years. The protocol for these checks is based on the model of opportunistic screening for cardiovascular risk factors that was developed at the Oxford Centre for Prevention in Primary $\mathrm{Care}^{67}$ and has since been adopted by many general practices in Oxfordshire and further afield. One of the fundamental tenets of this model is that opportunistic invitations to patients attending their general practitioner for routine consultations are an effective means of providing preventive services to all patients.

A record has been kept at the health centre of all invitations to attend a health check during the past five years, and therefore it has been possible to assess whether this assertion is true. Berinsfield has two advantages (other than good record keeping) that have helped in characterising attenders and non-attenders at health checks. Firstly, the practice, which lies about 16 $\mathrm{km}$ south of Oxford, has a diverse population. About half of the patients live in Berinsfield itself, which was developed as a local authority housing estate in the early 1960s on the site of a disused airfield. Residents of this estate are mainly from social classes III and IV, which contrasts with the bias towards social classes I and II of the remaining practice population, which is distributed among 10 villages within a $6 \mathrm{~km}$ radius of Berinsfield. Secondly, a lifestyle survey was sent to all patients in 1987 asking them about their smoking and 
dietary habits and their attitudes to prevention of disease.

\section{Methods}

HEALTH CHECKS

Health checks were introduced at Berinsfield in 1984 with the aim of screening all men and women aged 35 64 over a period of five years. The protocol for the checks was developed by the doctors, the treatment room nurses, and the receptionists during a series of lunchtime meetings. A nurse was employed to carry out the health checks. An additional two hour evening session a week was set aside for doing these checks, although appointments could be made for other times of the day. Each check lasted about half an hour. Different approaches were used for men and women. Whenever a man in the target age group came to the health centre the receptionists invited him to make an appointment for a health check and gave him an explanatory leaflet to read. In contrast, women in the target age group were sent a letter inviting them to attend for a health check and cervical smear test. Reminder letters were sent after four months to those who had not replied. The doctors reinforced these invitations verbally whenever they saw an eligible patient.

Notes were tagged with a blank sticker and the date of the health check was marked on this sticker when the patient attended. Information gleaned at the health checks was entered on to the Oxford community health project mainframe computer. For the purpose of our study a manual search was made of the medical records early in 1989 to identify patients with health check invitation stickers. At the time of this count there were 1101 men and 1110 women aged 35-64 registered with the practice.

\section{POSTAL QUESTIONNAIRES}

In the first half of 1987 every patient aged 16-64 years registered at the health centre was sent a postal questionnaire which asked about occupation, marital state, smoking habits, alcohol consumption, weight, height, and diet. A diet score was computed from responses to questions about the types of milk, bread, and fat used and from the number of times certain foods were consumed. An unhealthy diet was one high in saturated fat, low in fibre, and high in sugar. Questions were also asked about the motivation of patients to change their habits to a healthier lifestyle and about surgery attendance. Questionnaires were sent to $1315(90 \cdot 2 \%)$ of the 1458 patients who were invited for a health check and $1031(78 \cdot 4 \%)$ completed it. Complete data were available for 973 patients. Questionnaires were not sent to 143 patients because they had registered after 1987.

\section{QUESTIONNAIRE NON-COMPLETERS}

Information of age, sex, marital state, smoking habit, and social class of those who did not complete the questionnaire was gleaned from the medical

TABLE I-Characteristics of attenders and non-attenders at health checks ( $n=1393)$

\begin{tabular}{|c|c|c|c|c|c|c|c|}
\hline \multirow[b]{2}{*}{ Characteristic } & \multicolumn{3}{|c|}{ Attenders $(n=931)$} & \multicolumn{3}{|c|}{ Non-attenders $(n=462)$} & \multirow{2}{*}{$\begin{array}{c}\text { p Value } \\
\text { (attenders } \\
v \text { non- } \\
\text { attenders) }\end{array}$} \\
\hline & No & $\%$ & $\begin{array}{c}95 \% \\
\text { Confidence } \\
\text { interval }\end{array}$ & No & $\%$ & $\begin{array}{c}95 \% \\
\text { Confidence } \\
\text { interval }\end{array}$ & \\
\hline Male & 429 & $46 \cdot 1$ & 42.9 to 49.3 & 287 & $62 \cdot 1$ & 57.7 to 66.5 & $<0.001$ \\
\hline Age $<45$ & 349 & $37 \cdot 5$ & $34 \cdot 4$ to $40 \cdot 6$ & 199 & $43 \cdot 1$ & $38 \cdot 6$ to $47 \cdot 6$ & $<0.05$ \\
\hline Married & 795 & $85 \cdot 4$ & 83.1 to 87.7 & 362 & $78 \cdot 4$ & $74 \cdot 6$ to $82 \cdot 1$ & $<0.001$ \\
\hline Smokers* & 235 & $25 \cdot 2$ & $22 \cdot 4$ to $28 \cdot 0$ & 159 & $34 \cdot 4$ & $30 \cdot 1$ to 38.7 & $<0.001$ \\
\hline
\end{tabular}

${ }^{\star}$ In 19 attenders and 35 non-attenders smoking habit was not adequately recorded and percentages given are after exclusion of these subjects. records. At the time of the audit 65 records could not be identified (mainly because these patients had left the practice), leaving 1393 of the 1458 (95.5\%) patients who were invited for a check up about whom basic demographic information was known.

ANALYSIS

The analysis was done on the university mainframe computer with the statistical package for the social sciences (SPSS). Confidence intervals were calculated on the basis of the standard error of a proportion except where $\mathrm{n}<50$ and the exact interval is given based on the binomial distribution. Adjustment of relative risks was achieved with the generalised linear interactive modelling (GLIM) statistical package, and the statistical significance of the adjusted relative risk was assessed on the basis of the standard error of the odds ratio.

We were aware that the health checks might have influenced patients to change their behaviour, thus resulting in a reduction in risk factors for those who completed the questionnaire after their health checks. This might have led to an underestimation of the attendance rate in high risk categories. To measure this bias the analysis of the effect of expressed attitudes and reported risk factors was carried out independently for patients completing the questionnaire before and after the health check.

\section{Results}

Of the 2211 men and women in the target age group (35-64), $1458(65 \cdot 9 \%)$ had been invited for a health check during the previous five years (1984-9) and 963 $(43.6 \%$ of the target population, $66.0 \%$ of those invited) had attended a health check. On the basis of the 1393 patients for whom sociodemographic data were obtained, the attendance rates were $59.9 \%$ for men, $74 \cdot 2 \%$ for women; $63 \cdot 7 \%$ for those aged $<45$, $68 \cdot 9 \%$ for those aged $\geqslant 45 ; 68 \cdot 7 \%$ for married patients, $59.3 \%$ for single patients; $59.6 \%$ for smokers, $71 \cdot 6 \%$ for non-smokers. The characteristics of the attenders and non-attenders in terms of sex, age, marital state, and smoking habit are compared in table I. Patients attending health checks were more likely to be women, married, aged $\geqslant 45$, and non-smokers. Table II shows the association between social class and non-attendance. There was a significantly increasing trend in non-attendance from social class I $(16 \%)$ to social class $\mathrm{V}(38 \%)$

TABLE II - Non-attendance at health checks in 1031 patients according to social class ${ }^{\star}$

\begin{tabular}{lcccc}
\hline & & \multicolumn{3}{c}{ Non-attenders } \\
\cline { 3 - 5 } & & & & $\begin{array}{c}95 \% \\
\text { Confidence } \\
\text { interval }\end{array}$ \\
& $\begin{array}{c}\text { No of patients } \\
\text { invited }\end{array}$ & No & $\%$ & \\
Social class: & & & & \\
I & 105 & 17 & 16 & $9 \cdot 1$ to $23 \cdot 2$ \\
II & 286 & 75 & 26 & $21 \cdot 1$ to $31 \cdot 3$ \\
III Non-manual & 90 & 26 & 29 & $19 \cdot 5$ to $38 \cdot 3$ \\
III Manual & 268 & 80 & 30 & $24 \cdot 4$ to $35 \cdot 4$ \\
IV & 146 & 40 & 27 & $20 \cdot 2$ to $34 \cdot 6$ \\
V & 34 & 13 & 38 & $22 \cdot 2$ to $56 \cdot 4$ \\
Unclassified & 102 & 32 & 31 & $22 \cdot 4$ to $40 \cdot 4$
\end{tabular}

* Office of Population Censuses and Surveys classification based on own occupation or on partner's occupation in case of married women. $\chi^{2}$ For linear trend (excluding unclassified) $=5 \cdot 64, p=0 \cdot 02$

Table III examines the likelihood of non-attendance according to individual indicators of disease risk, again after adjustment for age, sex, martital state, and social class. Information was available only for people who responded to the questionnaire, and patients giving incomplete information were excluded. For each risk factor patients in the high risk categories exhibited non-attendance rates about $20-50 \%$ higher than patients 


\begin{tabular}{|c|c|c|c|c|c|c|}
\hline & \multirow{3}{*}{$\begin{array}{l}\text { No of } \\
\text { patients } \\
\text { invited }\end{array}$} & \multicolumn{3}{|c|}{ Non-attenders } & \multirow{2}{*}{\multicolumn{2}{|c|}{$\begin{array}{l}\text { Relative likelihood of } \\
\text { non-attendance }\end{array}$}} \\
\hline & & & & & & \\
\hline & & No & $\%$ & interval & Crude & Adjusted $\dagger$ \\
\hline \multicolumn{7}{|l|}{ Smoking state: } \\
\hline Non-smokers & 730 & 181 & $24 \cdot 8$ & $21 \cdot 7$ to $27 \cdot 9$ & 1.00 & \\
\hline Smokers & 243 & 81 & $33 \cdot 3$ & $27 \cdot 4$ to $39 \cdot 3$ & $1 \cdot 34$ & $1 \cdot 24$ \\
\hline \multicolumn{7}{|l|}{ Alcohol consumption (g/week): } \\
\hline$\leqslant 200($ Men $), \leqslant 150($ women $)$ & 842 & 220 & $26 \cdot 1$ & $23 \cdot 1$ to $29 \cdot 2$ & 1.00 & \\
\hline$>200($ men $),>150$ (women) & 131 & 42 & $32 \cdot 1$ & $24 \cdot 1$ to $40 \cdot 1$ & 1.23 & $1 \cdot 16$ \\
\hline \multicolumn{7}{|l|}{ Diet: } \\
\hline \multicolumn{7}{|l|}{ Score: } \\
\hline Healthy $(\geqslant 20)$ & 723 & 174 & $24 \cdot 1$ & $21 \cdot 0$ to $27 \cdot 2$ & 1.00 & \\
\hline Less healthy $(<20)$ & 250 & 88 & $35 \cdot 2$ & $29 \cdot 3$ to $41 \cdot 1$ & 1.46 & $1 \cdot 28$ \\
\hline \multicolumn{7}{|l|}{ Type of milk drink: } \\
\hline Skimmed or semiskimmed & 372 & 78 & $21 \cdot 0$ & $16 \cdot 9$ to $25 \cdot 1$ & 1.00 & \\
\hline Other $\neq$ & 601 & 184 & $30 \cdot 6$ & $26 \cdot 9$ to $34 \cdot 3$ & $1 \cdot 46$ & $1 \cdot 35$ \\
\hline \multicolumn{7}{|l|}{ Quetelet's index: } \\
\hline$<25$ & 571 & 137 & $24 \cdot 0$ & $20 \cdot 5$ to $27 \cdot 5$ & 1.00 & \\
\hline $25-29 \cdot 9$ & 314 & 99 & $31 \cdot 5$ & $26 \cdot 4$ to $36 \cdot 7$ & $1 \cdot 31$ & $1 \cdot 20$ \\
\hline$\geqslant 30$ & 88 & 26 & $29 \cdot 5$ & $20 \cdot 0$ to $39 \cdot 1$ & $1 \cdot 23$ & $1 \cdot 19$ \\
\hline
\end{tabular}

^ Expressed as relative risk.

†For age, sex, marital state, and social class.

$\ddagger$ Mainly full cream milk but includes 76 patients who did not drink cows’ milk.

TABLE IV - Non-attendance at health checks among specific groups of patients according to their expressed attitude to their behaviour

\begin{tabular}{|c|c|c|c|c|}
\hline & \multicolumn{4}{|c|}{ Non-attenders } \\
\hline & $\begin{array}{l}\text { No of patients } \\
\text { invited }\end{array}$ & No & $\%$ & $\begin{array}{c}95 \% \\
\text { Confidence } \\
\text { interval }\end{array}$ \\
\hline \multicolumn{5}{|l|}{ Heavy drinkers $(n=131)$ : } \\
\hline Want and intend to cut down & 13 & 5 & 39 & 13.9 to 68.4 \\
\hline Want but unlikely to cut down & 21 & 3 & 14 & 3.0 to $36 \cdot 3$ \\
\hline Don't want to cut down ${ }^{\star}$ & 97 & 33 & 34 & $24 \cdot 6$ to $43 \cdot 4$ \\
\hline \multicolumn{5}{|c|}{ Want $v$ don't want to cut down $\chi^{2}=1 \cdot 48, \mathrm{NS}$} \\
\hline \multicolumn{5}{|c|}{ Smokers $(n=243)$ : } \\
\hline Want and intend to stop smoking & 61 & 16 & 26 & $15 \cdot 2$ to $37 \cdot 3$ \\
\hline Want but unlikely to stop smoking & 131 & 40 & 31 & $22 \cdot 6$ to $38 \cdot 4$ \\
\hline Don't want to stop smoking & 51 & 25 & 49 & $35 \cdot 3$ to $62 \cdot 7$ \\
\hline$\chi^{2}$ For trend $=6 \cdot 13, p=0 \cdot 01$ & & & & \\
\hline \multicolumn{5}{|l|}{$\operatorname{All}(n=973)$} \\
\hline Eat healthy diet & 705 & 177 & 25 & $21 \cdot 9$ to $28 \cdot 3$ \\
\hline Eat unhealthy diet & 83 & 21 & 25 & $16 \cdot 0$ to $34 \cdot 7$ \\
\hline Not sure & 185 & 64 & 35 & $27 \cdot 7$ to $41 \cdot 4$ \\
\hline \multicolumn{5}{|l|}{ Sure $v$ unsure $\chi^{2}=6.82, \mathrm{p}<0.1$} \\
\hline
\end{tabular}

^Includes one patient who gave no answer.

† Includes eight patients who gave no answer

at lower risk, but after adjustment the increased likelihood of non-attendance was not significant for any individual risk factor. Combining risk factors did not significantly increase the estimated likelihood of attendance above that for individual risk factors alone. The adjusted likelihood of attendance of patients according to diet was similar whether this was measured by a composite score or by the type of milk drunk. Health check attendance was also compared with surgery consultation rates (as reported in the questionnaire). After exclusion of newly registered patients, non-attendance rates were $30.9 \%$ in those patients who consulted a doctor up to two times a year and $23.3 \%$ in those consulting four or more times a year $\left(\chi^{2}=7 \cdot 28\right.$, $\mathrm{p}<0.01)$. Frequent consulters were therefore more likely to attend health checks. As 496 health checks were carried out before the questionnaire was administered and because inclusion of patients who had changed their behaviour because of the health check would have led to an underestimation of the attendance rate in high risk categories, the analysis of subjects who completed the questionnaire before the health check was carried out independently from the analysis of those who completed it afterwards. There was no significant difference in attendance rates for these two groups and therefore the combined results are presented in table III. The non-attendance rate for smokers was $24.8 \%$ based on the questionnaire answers and $25 \cdot 4 \%$ based on the health check records.

Table IV shows the non-attendance rates among specific groups of subjects according to the attitudes they expressed to their alcohol consumption, smoking habits, and diet.

\section{Discussion}

Our study is of particular interest because it reviews one general practice's experience of health checks over five complete years. Despite our intention to invite each of our patients aged 35-64 for a health check over this period we ultimately succeeded in offering a check to only $66 \%$ and completing a health check in only $44 \%$. This result is disappointingly low and contrasts with the reports of others who have described health check attendance rates as high as $92 \% .{ }^{8}$ Our sense of unfulfilment is compounded by the commitment of the practice to the project, which entailed considerable changes in practice organisation; increased workload for the receptionists, treatment room nurses, and doctors; additional computing facilities; and occasional support from facilitators.

Our unexpectedly low invitation and attendance rates might have paradoxically been due to the length of our study. Sacks and Marsden reported their attendance figures after only two years, ${ }^{8}$ but we found that recruitment was much higher in the early stages of the project and then dwindled progressively as staff enthusiasm waned and the practice's more frequent consulters had received invitations. In addition, over the five years the turnover of the practice began to exert an appreciable influence. At Berinsfield the turnover of patients is $10 \%$ yearly, with the result that many patients who had health checks were lost only to be replaced by unchecked new patients. The difference in attendance between men and women might also reflect the method of recruitment: women were invited by letter and were also offered a cervical smear test, and this might have contributed to their higher rate of attendance.

Attendance for preventive health care also depends on the motivation and attitudes of individual patients and their perception of its benefit to them..$^{9-11}$ Smokers who said that they were highly motivated to give up the habit were more likely to attend than smokers reporting no intention of cutting down, but interestingly no such trend was shown in heavy drinkers or in those with inappropriate dietary habits (table IV). Unfortunately, patients with recognised risk factors, who consequently would potentially benefit most from a health check, were least likely to attend (so fulfilling Hart's inverse care law), whereas frequent consulters were more likely to attend, although the social class gradient for non-attendance was less noticeable than in other studies. ${ }^{51213}$

Can the limitations of health checks be overcome and their effectiveness enhanced? It is true that people from social classes IV and V tend to consult more often and that every visit to a health centre or surgery provides an opportunity for health promotion..$^{14}$ One strategy for reaching these high risk patients would be to provide additional medical and nursing time during routine consultations instead of relying on the patient to return at some future date for a formal health check. Alternatively, compliance might be improved by inviting the targeted patient and his or her family, with the ensuing family consultation taking place in the surgery or at the patients' home (L Pike, personal communication). Marsh and Channing have described a 15 month campaign by their primary health care team to raise the uptake of preventive care in their deprived practice population. ${ }^{15}$ This was achieved by rigorous monitoring and organisation, with patients at risk being carefully selected and approached directly rather than the practice waiting passively for them to arrange a consultation. It must also be remembered that the Black report ascribed the low uptake of preventive services among social classes IV and $\mathrm{V}$ to the self perpetuating cycle of socioeconomic deprivation. ${ }^{16} \mathrm{~A}$ healthy diet is comparatively expensive for those with a low income; smoking and alcohol consumption might 
compensate for the stress of living in a poor environment; and recreational facilities are not as accessible for people with no transport or who have small children. ${ }^{17}$ These factors might need to be modified first if the promotion of healthier lifestyles is to be successful.

The new contract requires general practitioners to provide checks every three years for patients aged 1674 years. It is thus of some concern that our findings reinforce those of other studies suggesting that unselective health checks might be an inefficient use of valuable resources and might promote further inequalities in health. Despite their simplicity and economic attractiveness health checks may have only a limited part to play in any comprehensive plan for health promotion as they cater primarily for the fitter and better motivated members of the public. The global strategy required to combat ischaemic heart disease must incorporate political will, in the form of public education and strong price and advertising controls to reduce the consumption of saturated fats and tobacco, as well as enthusiasm, organisation, and vigilance by primary health care teams. The medical profession should not be cajoled into accepting complete responsibility for health promotion and the prevention of ischaemic heart disease, so absolving the government of its obligations.

We thank the patients and staff of the Berinsfield Health Centre and the staff and resources of the Oxford community health project and the University of Oxford Department of Community Medicine and General Practice. Our study was supported by a grant from the Scientific Foundation Board of the Royal College of General Practitioners. DM, LJ, and AF are supported by the Imperial Cancer Research Fund. The Unit of Clinical Epidemiology is funded by the Department of Health and by Oxford Regional Health Authority.

1 Secretaries of State for Social Services, Wales, Northern Ireland, and Scotland Promoting better health. London: HMSO, 1987. (Cmnd 249.)

2 Department of Health. General practice in the National Health Service: the 1990 contract. London: Department of Health, 1989.

3 Hart J T. The inverse care law. Lancet 1971;i:405-12. Pr, Juality? I R Coll Gen Pract 1989;39:196-9.
or

5 Pill R, French J, Harding K, Stott NCH. Invitation to attend a health check in a general practice setting: comparison of attenders and non-attenders. $\mathcal{F} R$ Coll Gen Pract 1988;38:53-6.

6 Fullard EM, Fowler GJ, Gray JAM. Facilitating prevention in primary care. BrMed f 1984;289:1585-7.

7 Fullard EM, Fowler GH, Gray JAM. Promoting prevention in primary care: controlled trial of low technology low cost approach. Br Med J 1987 294: $1080-2$.

8 Sacks G, Marsden R. Evaluation of a practice-based programme of health checks: financial cost and success at risk detection. $f R$ Coll Gen Pract 1989;39:369-72.

9 Pill R, Stott N. Invitation to attend a health check in a general practice setting: the views of a cohort of non-attenders. $\mathcal{F} R$ Coll Gen Pract 1988;38:57-60.

$10 \mathrm{Vijay} \mathrm{N}$. Investigation of non-responders at a cervical cancer screening clinic in Manchester. BrMed F 1988;296:1041-2.

11 Coulter A, Baldwin A. Survey of population coverage in cervical cancer screening in the Oxford region. $f R$ Coll Gen Pract 1987;37:441-3.

12 Wrench J. Irvine $R$. Coronary heart disease: account of a preventative clinic in rench J, Irvine R. Coronary heart disease: account of
general practice. $\mathcal{F}$ R Coll Gen Pract 1984;34:477-81.

13 French K, Porter ADM, Rolinson SE, McCallum FM, Howie JGR, Roberts MM. Attendance at a breast screening clinic: a problem of administration or attitudes? $\mathrm{Br}$ Med $\mathcal{F}$ 1982;285:617-20

14 Smail SA. Opportunities for prevention: the consultation. $\mathrm{Br} \mathrm{Med} \mathcal{f} 1982$ 284: 1092-3.

15 Marsh GN, Channing DM. Narrowing of the health gap between a deprived and an endowed community. Br Med F 1988;296:173-6.

16 Townsend P, Davidson N. Inequalities in health: the Black report. London: Penguin, 1982.

17 Coulter A. Lifestyles and social class: implications for primary care. $\mathcal{J} R \mathrm{Coll}$ Gen Pract 1987:37:533-6.

(Accepted 6 February 1990)

\title{
Screening in Practice
}

\section{Maternal and fetal screening for antenatal care}

\author{
M J V Bull
}

The chief aim of antenatal care is to maintain and improve the health of both mother and fetus during pregnancy so that they are in optimum condition when parturition occurs. Subsidiary objectives are the early diagnosis of variations from the norm and the detection of asymptomatic, potentially threatening conditions that may arise. Screening is, in fact, a term that broadly covers this process of detection and for many years it has been accepted as an integral part of good maternity care. The procedures used were at first mainly directed at preserving the wellbeing of the mother but, particularly during the last two decades, innovative techniques have been introduced that enable indirect but sophisticated monitoring of the fetus.

\section{Screening before conception}

Preparation for pregnancy can sometimes be combined with the provision of contraceptive advice. For example, rubella state should be determined, and if the woman is not immune she can be immunised before contraception is abandoned. Many women are increasingly concerned about other infective hazards to the fetus, such as toxoplasmosis, so a comprehensive serum TORCH screen (toxoplasmosis, rubella, cytomegalovirus, herpes virus) may be appropriate, at least from the viewpoint that a mother shown to be immune to these conditions can be reassured that reinfection during pregnancy is unlikely. At the same time the woman's $\mathrm{ABO}$ blood group and rhesus factor should be determined (if they are not already known) to warn of the possibility of isoimmunisation during pregnancy. Similarly, haemoglobinopathies should be looked for-for example, sickle trait in Afro-Caribbean women and thalassaemia in those of Mediterranean or Asian origin.

A family history should also be obtained regarding possible genetic anomalies, and if any are present formal genetic counselling should be arranged before conception occurs. This is especially necessary where there is a history of X-linked or autosomal defects, chromosomal rearrangement, or any major developmental abnormality. A considerable advance in preconceptual counselling has been the development of a technique for gene tracking in prospective parents and their families. It uses DNA probes and markers and allows assessment for the risk of such conditions as Huntington's chorea, cystic fibrosis, muscular dystrophy (Becker, Duchenne, or myotonic), neurofibromatosis, and familial polyposis coli as well as haemophilia $\mathrm{A}$ and $\mathrm{B}$ and the haemoglobinopathies. Guidelines on multistage screening and tests for carrier states were published in 1987 in the King's Fund consensus statement on screening for fetal and genetic abnormality.'

\section{Screening during pregnancy}

Screening procedures during pregnancy can conveniently be associated with the key points during antenatal care when the mother would be seen by her doctor $^{2}$ rather than by her midwife. These are at 